\title{
Vitamin D: An Evidence-Based Review
}

\author{
Teresa Kulie, MD, Amy Groff, DO, Jackie Redmer, MD, MPH, Jennie Hounshell, MD, \\ and Sarina Schrager, $M D, M S$
}

\begin{abstract}
Vitamin $D$ is a fat-soluble vitamin that plays an important role in bone metabolism and seems to have some anti-inflammatory and immune-modulating properties. In addition, recent epidemiologic studies have observed relationships between low vitamin D levels and multiple disease states. Low vitamin D levels are associated with increased overall and cardiovascular mortality, cancer incidence and mortality, and autoimmune diseases such as multiple sclerosis. Although it is well known that the combination of vitamin $D$ and calcium is necessary to maintain bone density as people age, vitamin $D$ may also be an independent risk factor for falls among the elderly. New recommendations from the American Academy of Pediatrics address the need for supplementation in breastfed newborns and many questions are raised regarding the role of maternal supplementation during lactation. Unfortunately, little evidence guides clinicians on when to screen for vitamin $D$ deficiency or effective treatment options. $(J$ Am Board Fam Med 2009;22:698-706.)
\end{abstract}

\section{Background and Physiology}

Vitamin D is a hormone precursor that is present in 2 forms. Ergocalciferol, or vitamin $\mathrm{D}_{2}$, is present in plants and some fish. Cholecalciferol, or vitamin $\mathrm{D}_{3}$, is synthesized in the skin by sunlight. Humans can fulfill their vitamin $\mathrm{D}$ requirements by either ingesting vitamin $\mathrm{D}$ or being exposed to the sun for enough time to produce adequate amounts. Vitamin $\mathrm{D}$ controls calcium absorption in the small intestine and works with parathyroid hormone to mediate skeletal mineralization and maintain calcium homeostasis in the blood stream. In addition, recent epidemiologic studies have observed relationships between low vitamin D levels and multiple disease states, probably caused by its anti-inflammatory and immune-modulating properties and possible affects on cytokine levels.

Vitamin $\mathrm{D}_{3}$ can be manufactured in the skin by way of ultraviolet (UV) B rays. UVB rays are present only during midday at higher latitudes and do not penetrate clouds. The time needed to pro-

This article was externally peer reviewed.

Submitted 27 February 2009; revised 10 July 2009; accepted 13 July 2009.

From the Department of Family Medicine, University of Wisconsin, Madison.

Funding: none.

Conflict of interest: none declared.

Corresponding author: Sarina Schrager, MD, MS, Department of Family Medicine, University of Wisconsin, $777 \mathrm{~S}$. Mills St., Madison, WI 53715 (E-mail: sbschrag@wisc.edu). duce adequate vitamin $\mathrm{D}$ from the skin depends on the strength of the UVB rays (ie, place of residence), the length of time spent in the sun, and the amount of pigment in the skin. Tanning beds provide variable levels of UVA and UVB rays and are therefore not a reliable source of vitamin D.

Vitamin $\mathrm{D}_{3}$ is synthesized from 7-dehydrocholesterol in the skin. The vitamin $\mathrm{D}$ binding protein transports the vitamin $\mathrm{D}_{3}$ to the liver where it undergoes hydroxylation to $25(\mathrm{OH}) \mathrm{D}$ (the inactive form of vitamin D) and then to the kidneys where it is hydroxylated by the enzyme $1 \alpha$ hydroxylase to $1,25(\mathrm{OH}) \mathrm{D}$, its active form. ${ }^{1}$ This enzyme is also present in a variety of extrarenal sites, including osteoclasts, skin, colon, brain, and macrophages, which may be the cause of it's broad-ranging effects. ${ }^{1}$ The half-life of vitamin D in the liver is approximately 3 weeks, which underscores the need for frequent replenishment of the body's supply.

\section{Vitamin D and Mortality}

Vitamin D may be a determinant of mortality because of its anti-inflammatory and immune-modulating effects. It has been used to treat secondary hyperparathyroidism in people on dialysis. Retrospective trials show that vitamin $\mathrm{D}$ supplementation is associated with decreased mortality in people on dialysis. ${ }^{2}$ Low serum vitamin D levels are also related to increased mortality in most patients with chronic kidney disease before dialysis. ${ }^{3}$ How- 
ever, there have been no randomized prospective trials examining this relationship. ${ }^{4}$

In patients not on dialysis, low vitamin $\mathrm{D}$ levels are associated with increased levels of inflammation and oxidative load. A prospective study of more than 3000 male and female patients scheduled for coronary angiography found a positive association between low vitamin D levels and cardiovascular as well as all-cause mortality. ${ }^{5}$ Data analysis from the National Health and Nutrition Examination Survey III (more than 13,000 adults) showed that people with vitamin D levels in the lowest quartile had a mortality rate ratio of 1.26 (95\% CI, $1.08-1.46){ }^{6}$ A recent meta-analysis demonstrated that intake of a vitamin $\mathrm{D}$ supplement at normal doses also was associated with decreased all-cause mortality rates. ${ }^{7}$ These data suggest that vitamin D may play a part in multiple causes of death, although causality has not been determined.

\section{Vitamin D and Cardiovascular Disease}

Vitamin D receptors are present in vascular smooth muscle, endothelium, and cardiomyocytes and may have an impact on cardiovascular disease. Observational studies have shown a relationship between low vitamin D levels and blood pressure, coronary artery calcification, and existing cardiovascular disease. A large cohort study that included more than 1700 participants from the Framingham offspring study looked at vitamin D levels and incident cardiovascular events. ${ }^{8}$ During a period of 5 years, participants who had 25-OH D levels of $<15$ were more likely to experience cardiovascular events (hazard ratio, 1.62; 95\% CI, 1.11-2.36). The relationship remained significant among people with hypertension but not among those without hypertension. $^{8}$

\section{Vitamin D and Diabetes}

Recent studies in animal models and humans have suggested that vitamin D may also play a role in the homeostasis of glucose metabolism and the development of type 1 and type 2 diabetes mellitus (DM). Epidemiologic data has long suggested a link between exposure to vitamin D early in life and the development of type $1 \mathrm{DM}^{9,10}$ Vitamin $\mathrm{D}_{3}$ receptors have strong immune-modulating effects. In some populations the development of type $1 \mathrm{DM}$ is associated with polymorphisms in the vitamin $\mathrm{D}$ receptor gene. ${ }^{11,12}$ There is also some evidence that increased vitamin $\mathrm{D}$ intake by infants may reduce the risk of the development of type $1 \mathrm{DM}^{13}$

Vitamin D has recently been associated with several of the contributing factors known to be linked to the development of type $2 \mathrm{DM}$, including defects in pancreatic $\beta$ cell function, insulin sensitivity, and systemic inflammation. Several physiologic mechanisms have been proposed, including the effect of vitamin $\mathrm{D}$ on insulin secretion, the direct effect of calcium and vitamin $\mathrm{D}$ on insulin action, and the role of this hormone in cytokine regulation. ${ }^{9,12,13}$ Although most studies indicating this relationship are observational, one meta-analysis showed a relatively consistent association between low vitamin D status, calcium or dairy intake, and prevalence of type 2 DM or metabolic syndrome. The study concluded that the highest type 2 DM prevalence, 0.36 (95\% CI, 0.16-0.80), among participants who were not black was associated with the lowest blood levels of 25-hydroxyvitamin D. In addition, metabolic syndrome prevalence of 0.71 (95\% CI, 0.57-0.89) was highest among those with the lowest dairy intake. There was also an inverse relationship between type $2 \mathrm{DM}$ and metabolic syndrome incidences and vitamin $\mathrm{D}$ and calcium intake. ${ }^{14}$

\section{Vitamin D and Osteoporosis}

Osteoporosis is the most common metabolic bone disease in the world. A low vitamin D level is an established risk factor for osteoporosis. Inadequate serum vitamin $\mathrm{D}$ levels will decrease the active transcellular absorption of calcium.

Although combination calcium and vitamin D supplementation is associated with higher bone mineral density and decreased incidence of hip fractures ${ }^{15}$ the evidence for vitamin D supplementation alone is less clear. A recent evidence summary found that vitamin $\mathrm{D}$ supplementation at doses of more than 700 IU daily (plus calcium) prevented bone loss compared with placebo. ${ }^{16}$ However, vitamin D supplementation (300 to 400 IU daily) without calcium did not affect fractures. ${ }^{16}$ A Cochrane review found unclear evidence that vitamin $\mathrm{D}$ alone affected hip, vertebral, or other fracture rates but supported the use of vitamin D with calcium in frail, elderly nursing home residents. ${ }^{17}$ A subsequent meta-analysis of trials looking at vitamin $\mathrm{D}$ and fracture rates concurred that calcium was also necessary to affect a significant difference. $^{18}$ 
The most recent meta-analysis of 12 randomized, controlled trials that included more than 42,000 people found that vitamin D supplementation of more than 400 IU daily slightly reduced incidence of nonvertebral fractures (rate ratio, 0.86; 95\% CI, 0.77-0.96). ${ }^{19}$ The effect was dose dependent and was not significant if doses were $\leq 400 \mathrm{IU}$ daily.

\section{Vitamin D and Falls among the Elderly}

Vitamin D status is increasingly recognized as an important factor in fall status among elderly patients. Several trials have demonstrated that vitamin D supplementation decreases the risk of falling. One proposed mechanism is that higher vitamin D levels are associated with improved muscle function.

A randomized, controlled trial from Australia evaluated women with at least one fall in the preceding 12 months and with a plasma 25 -hyroxyvitamin D level $<24.0 \mathrm{ng} / \mathrm{mL}^{.20}$ All women were given calcium $1000 \mathrm{mg}$ per day and were randomized to receive either ergocalciferol 1000 IU per day or placebo. Women in the study group had fewer falls after 12 months, but this was not a significant difference $(53 \%$ versus $62.9 \%$; odds ratio, 0.66 ; 95\% CI, 0.41-1.06). After correction for height difference in the 2 groups, the ergocalciferol group had a significantly lower risk of falling (odds ratio, $0.61 ; 95 \% \mathrm{CI}, 0.37-0.99)$.

A dose of 800 IU daily significantly reduced the risk of falling compared with a placebo in a dosestratified analysis of the effect of 5 months of vitamin D supplementation on fall risk ( $72 \%$ lower incidence rate ratio; rate ratio, 0.28 ; $95 \% \mathrm{CI}, 0.10$ $0.75)$. Lower doses of vitamin $\mathrm{D}$, however, did not significantly change the rate of fall incidence compared with placebo. ${ }^{21}$

A review of 12 randomized, controlled trials studying the effect of vitamin D supplementation on fall risk among both nursing home residents and community dwellers found a small benefit of supplementation on fall risk (odds ratio, 0.89; $95 \%$ CI, $0.80-0.99),{ }^{9}$ an effect that was also shown in a review of randomized, controlled trials with strict inclusion criteria, which included 1237 men and women with a mean age of 70 years and supplementation for 2 months to 3 years. The pooled results showed a significant $22 \%$ decrease in fall risk among those treated with vitamin $\mathrm{D}$ versus placebo or calcium only. The number needed to treat from the pooled results was 15 to prevent 1 person from falling ${ }^{22}$ Assessing vitamin D levels in a population at high risk for falling and supplementing with 800 to 1000 IU daily of vitamin D should be a part of any fall prevention program.

\section{Vitamin D and Cancer}

Both observational studies in humans and animal models support that vitamin D has a beneficial role in cancer prevention and survival. The mechanism of action is probably related to its role in the regulation of cell growth and differentiation. ${ }^{23}$ In the Health Professionals Follow-Up study (a cohort study of $1095 \mathrm{men}$ ), each increment in $25(\mathrm{OH}) \mathrm{D}$ level of $25 \mathrm{mmol} / \mathrm{L}$ was associated with a $17 \%$ reduction of total cancer cases. ${ }^{24}$ However, the National Health and Nutrition Examination Survey of 16,818 men and women did not find a relationship between total cancer mortality and vitamin D level. There was an inverse relationship between vitamin D level and colorectal cancer, however. In this study, serum $25(\mathrm{OH}) \mathrm{D}$ levels of $\geq 80 \mathrm{nmol} / \mathrm{L}$ conferred a $72 \%$ reduction in risk of colorectal cancer compared with a level lower than $50 \mathrm{nmol} / \mathrm{L}^{25}$

A recent meta-analysis of 63 observational studies looked at the relationship between vitamin D levels and cancer incidence and mortality. ${ }^{26}$ Twenty of the 30 studies looking at vitamin D and colon cancer showed that people with higher vitamin D levels had either a lower incidence of colon cancer or decreased mortality. Similarly, 9 of the 13 studies about breast cancer and 13 of the 26 studies about prostate cancer showed beneficial effects of vitamin $\mathrm{D}$ levels on cancer incidence or mortality (some of the studies included more than one type of cancer). ${ }^{26}$

A population-based randomized, control trial found that postmenopausal women who were supplemented with calcium and vitamin $\mathrm{D}$ had a reduced risk of cancer after the first year of treatment (rate ratio, 0.232; 95\% CI, 0.09-0.60)..$^{27}$ There was not a group that was supplemented with vitamin D alone.

\section{Vitamin D and Multiple Sclerosis}

Multiple sclerosis (MS) is a neurodegenerative, T lymphocyte-mediated, autoimmune disease of uncertain etiology. Although genetic susceptibility may be involved, epidemiologic studies suggest environmental influence because the development of MS correlates most strongly with rising latitude in 
both the northern and southern hemispheres. ${ }^{28}$ Migration studies show that risk can be modified at an early age from both low to high and high to low prevalence rates. ${ }^{28}$ Exposure to sun in early childhood is associated with reduced risk of developing $\mathrm{MS}^{29}$ and population-based studies about MS in Canada have also shown that birth timing is a risk factor for MS because there are statistically significantly fewer patients with MS born in November and more born in May compared with controls. ${ }^{30} \mathrm{~A}$ birth-timing association suggests that seasonality and sunlight exposure may also have an effect on the developing fetus in utero. ${ }^{30,31}$

Several studies have shown that vitamin D affects the growth and differentiation of immunemodulator cells such as macrophages, dendritic cells, T cells, and B cells. ${ }^{32-34}$ This immune-modulatory effect has implications for a variety of autoimmune diseases including rheumatoid arthritis, systemic lupus erythematosous, type I DM, inflammatory bowel disease, and MS. ${ }^{33}$

Despite the wealth of epidemiologic studies supporting a relationship between vitamin D and MS in humans, data showing a link between serum vitamin D levels and MS are only beginning to emerge. One prospective, nested, case-control study examined the serum samples of 7 million military veterans and compared serum samples of 257 MS patients before diagnosis with those of matched controls. ${ }^{35}$ An inverse relationship between vitamin D levels and MS risk was found, particularly for vitamin $\mathrm{D}$ levels measured in patients younger than 20. Another case-control study compared the serum vitamin D levels of 103 MS patients with 110 controls and found that for every $10-\mathrm{nmol} / \mathrm{L}$ increase of serum $25(\mathrm{OH}) \mathrm{D}$ level the odds of MS was reduced by $19 \%$ in women, suggesting a "protective" effect of higher vitamin D levels. ${ }^{36}$ In addition, a negative correlation was found between Expanded Disability Status Scale scores among female MS patients and 25(OH)D levels. Several other studies have supported the finding that lower levels of vitamin D in MS patients are associated with more severe disability. ${ }^{37}$ Lower levels during relapses have also been reported in patients with relapse-remitting MS. ${ }^{38-40}$

The potential effects of oral vitamin $\mathrm{D}$ intake have been observed in several different ways. A Norwegian case-control study found that fish and cod liver oil have a protective effect against the development of $\mathrm{MS}^{29}$ A large observational study in the United States that followed 2 large cohorts of women-the Nurses' Health Study (92,253 women followed from 1980 to 2000) and the Nurses' Health Study II (95,310 women followed from 1991 to 2001) - found that vitamin D supplementation in the form of a multivitamin seemed to lower their MS risk by $40 \% .^{41}$ However, several methodological weaknesses in study design made the results inconclusive. ${ }^{42}$

Despite the overwhelming amount of data describing the association between vitamin $\mathrm{D}$ and MS, there is a paucity of research describing the benefit of vitamin D supplementation to these patients. One small safety study of 12 patients taking $1000 \mu \mathrm{g}$ per day $(40,000 \mathrm{IU})$ of vitamin D for 28 weeks showed a decline in the number of gadolinium-enhancing lesions on magnetic resonance imaging per patient; this led to a $25(\mathrm{OH}) \mathrm{D}$ serum concentration of $386 \mathrm{nmol} / \mathrm{L}(158 \mathrm{ng} / \mathrm{mL})$ without causing hypercalcemia, hypercalciuria, or other complication. ${ }^{43}$

\section{Vitamin D and Cognition}

Observational studies have shown that people with Alzheimer dementia have lower vitamin D levels than do matched controls without dementia. ${ }^{44}$ The biological plausibility of this relationship includes vitamin D's antioxidative effects and the presence of vitamin D receptors in the hippocampus, which has been seen in rats and humans. ${ }^{44} \mathrm{~A}$ cross-sectional study of 225 outpatients diagnosed with Alzheimer disease found a correlation between vitamin D levels (but not other vitamin levels) and their score on a Mini Mental Status Examination. ${ }^{45}$

\section{Vitamin D and Chronic Pain}

Because of the important role vitamin D plays in bone homeostasis, some have questioned whether vitamin $\mathrm{D}$ deficiency may also correlate with chronic pain syndromes, including chronic low back pain. Several case series and observational studies have suggested that vitamin D inadequacy may represent a source of nociception and impaired neuromuscular functioning among patients with chronic pain.

The data to support this conclusion are mixed. A recent review of 22 relevant studies found no convincing link between prevalence and latitude and no association between serum levels of $25-\mathrm{OH}$ vitamin $\mathrm{D}$ in chronic pain patients and controls. Interestingly, though, there was a contrast in treat- 
ment effects between randomized, double-blind trials that minimized bias and those with studies known to be subject to bias. In those that blinded the vitamin D therapy, only $10 \%$ of patients were in trials showing a benefit of vitamin D treatment, whereas among those who did not blind the treatment $93 \%$ were in trials showing a benefit of vitamin D supplementation. ${ }^{46}$

A second review examined the role of vitamin deficiency in patients from outpatient and inpatient rehab units. Fifty-one articles were reviewed and a direct correlation was noted between vitamin D deficiency and musculoskeletal pain. Treatment of vitamin D deficiency produced an increase in muscle strength and a marked decrease in back and lower-limb pain within 6 months. ${ }^{47}$ Although these data were suggestive of a link between vitamin D and pain, the available evidence does not imply causality. The verdict on this topic will remain undecided until this is evaluated by double-blind, randomized, controlled trials stratified by baseline vitamin $\mathrm{D}$ level with defined treatments and comparison placebo groups.

\section{Vitamin D Supplementation for Infants and Breastfeeding Mothers}

Breast milk is an ideal form of nourishment for a newborn. Because of most nursing mother's own vitamin $\mathrm{D}$ deficiency, however, and despite the mother taking a prenatal vitamin, breast milk alone is not sufficient to maintain newborn vitamin D levels within a normal range. ${ }^{48}$ Many nursing mothers or their infants require vitamin D supplementation for optimal health. ${ }^{49}$

In 2003, the American Academy of Pediatrics recommended that $200 \mathrm{IU}$ of vitamin D be used as supplementation for all infants beginning during the first 2 months after birth. ${ }^{50}$ More recently, in 2008 the recommendation has been increased to a minimum of 400 IU daily during the first days of life to prevent vitamin $\mathrm{D}$ deficiency that may lead to rickets. $^{48}$

A 2004 systematic review looked at 166 cases of nutritional rickets diagnosed between 1986 and 2004 in 17 states from the mid-Atlantic region to Texas and Georgia. A disproportionate number of rickets cases were found in African-American, breastfed infants. ${ }^{51}$ In addition to rickets and the risk of developing type I DM, other pediatric and adult health conditions may be impacted by insuf-
Table 1. Vitamin D Preparations for Newborns

\begin{tabular}{lcc}
\hline Preparation & Dose & Comments \\
\hline $\begin{array}{l}\text { Just D by Sunlight } \\
\text { vitamins }\end{array}$ & $400 \mathrm{IU}$ in $1 \mathrm{~mL}$ & \\
Carson labs & $400 \mathrm{IU}$ gelcap & \\
Polyvisol & $400 \mathrm{IU}$ & $\begin{array}{c}\text { Also contains other } \\
\text { vitamins }\end{array}$ \\
\hline
\end{tabular}

ficient vitamin D levels in infants and their mothers. ${ }^{52}$ Both bone mineral accrual in early childhood $^{53}$ and the risk of recurrent wheezing episodes in children at age $3^{54}$ were linked to insufficient vitamin $\mathrm{D}$ intake by women during pregnancy. If a fetus or breastfeeding infant receives an inadequate amount of vitamin $\mathrm{D}$ from its mother it can have a direct impact on the baby's health as an adult. Because of these findings, in 2007 the Canadian Pediatric Society recommended 2000 IU of vitamin $\mathrm{D}_{3}$ for pregnant and lactating mothers with periodic blood tests to check levels of $25(\mathrm{OH}) \mathrm{D}$ and calcium. ${ }^{52}$ The American Academy of Pediatrics recommendations focus on supplementing the infant and make no specific recommendations about universally supplementing breastfeeding mothers. ${ }^{48}$

\section{Supplementing the Newborn: 2008 Recommendations from the American Academy of Pediatrics}

The American Academy of Pediatrics recommends supplementing all children who are exclusively breastfed with $400 \mathrm{IU}$ of vitamin D from the first few days of life. Children who are fed by breast and formula or who are exclusively formula fed should also be supplemented until they are consistently ingesting $1 \mathrm{~L}$ of formula a day (approximately 1 quart). The supplementation should continue until 1 year of age, when children begin ingesting vitamin D-fortified milk. ${ }^{48}$ All formulas sold in the United States contain at least 400 IU/L of vitamin $\mathrm{D}_{3}$; therefore, $1 \mathrm{~L}$ per day would meet the vitamin $\mathrm{D}$ recommendations set by the American Academy of Pediatrics. ${ }^{55}$

\section{Preparations for Supplementation}

There are many available preparations for newborns (Table 1). Some companies make a singledrop preparation that contains $400 \mathrm{IU}$, but caution should be used when prescribing this product because of the ease of dispensing too much vitamin D to a newborn with just a few drops. ${ }^{48}$ 


\section{Checking Serum Levels in Infants}

Clinicians should obtain a serum vitamin D level (25-OH-D not $1,25-\mathrm{OH}_{2}$-D) among infants with malabsorption disorders or who take anticonvulsants because they may need additional supplementation above 400 IU daily. Actual values of 25$\mathrm{OH}-\mathrm{D}$ that determine vitamin $\mathrm{D}$ insufficiency in children have not been defined. The $\geq 20 \mathrm{ng} / \mathrm{mL}$ of $25-\mathrm{OH}-\mathrm{D}$ that determines a sufficient vitamin $\mathrm{D}$ level for adults has been used for children. ${ }^{48}$

\section{Supplementing Breastfeeding Mothers}

Mothers who were supplemented with 400 IU of vitamin $\mathrm{D}$ daily produced milk with vitamin $\mathrm{D}$ levels that ranged from $<25$ to $78 \mathrm{IU}$ per liter. $^{48}$ Supplementing the mother alone with 400 IUequivalent to a prenatal vitamin-produced inadequate vitamin $\mathrm{D}$ levels in the breastfed infants. ${ }^{55} \mathrm{~A}$ randomized, controlled trial evaluated 19 breastfeeding mothers who were supplemented with 6000 IU of vitamin $\mathrm{D}_{3}$ and a prenatal vitamin with 400 IU of vitamin D. The vitamin D levels found in their breast milk and in the exclusively breastfed infants themselves were found to be equivalent to the infants who received oral supplementation (300 IU per day). This level of maternal supplementation showed no toxic effects and provided adequate vitamin $\mathrm{D}$ to nursing infants without needing to supplement the infant. ${ }^{56}$ Safety and efficacy of this dosing during pregnancy and lactation has not been confirmed. In the meantime, screening high-risk women is appropriate and supplementing breastfeeding women who are vitamin $\mathrm{D}_{3}$ deficient is warranted. ${ }^{57}$

\section{Testing for Vitamin D Deficiency}

There are many causes of vitamin D deficiency, as listed in (Table 2), ${ }^{59}$ and despite growing attention to this deficiency, there are no established guidelines to help clinicians decide which patients warrant screening laboratory testing. The US Preventive Services Task Force does not comment for or against routine screening for vitamin D deficiency. One approach is to consider serum testing in patients at high risk for vitamin D deficiency but treating without testing those at lower risk.

An Australian working group issued a position statement itemizing groups of people at risk for vitamin D deficiency. The risk groups include: (1) older people in low- and high-level residential care;
Table 2. Causes of Vitamin D Deficiency ${ }^{58}$

\begin{tabular}{|c|c|}
\hline Causes & Example \\
\hline Reduced skin synthesis & $\begin{array}{c}\text { Sunscreen, skin pigment, } \\
\text { season/latitude/time of } \\
\text { day, aging, skin grafts }\end{array}$ \\
\hline Decreaseed absorption & $\begin{array}{l}\text { Cystic fibrosis, celiac } \\
\text { disease, whipple disease, } \\
\text { Crohn disease, gastric } \\
\text { bypass, medications that } \\
\text { reduce cholesterol } \\
\text { absorption }\end{array}$ \\
\hline Increased sesquestration & Obesity \\
\hline Increased catabolism & $\begin{array}{l}\text { Anticonvulsant, } \\
\text { glucocorticoid, highly } \\
\text { active antiretroviral } \\
\text { treatment, and some } \\
\text { immunosuppressants }\end{array}$ \\
\hline \multicolumn{2}{|l|}{ Breastfeeding } \\
\hline $\begin{array}{l}\text { Decreased synthesis of } 25- \\
\text { hydroxyvitamin D }\end{array}$ & Hepatic failure \\
\hline $\begin{array}{l}\text { Increased urinary loss of } \\
\text { 25-hydroxyvitamin D }\end{array}$ & Nephrotic proteinuria \\
\hline $\begin{array}{l}\text { Decreased synthesis of } 1,25- \\
\text { dihydroxyvitamin D }\end{array}$ & Chronic renal failure \\
\hline Heritable disorders & $\begin{array}{l}\text { Genetic mutations causing } \\
\text { rickets, or vitamin D } \\
\text { resistance }\end{array}$ \\
\hline Acquired disorders & $\begin{array}{l}\text { Tumor-induced } \\
\text { osteomalacia, primary } \\
\text { hyperparathyroidism, } \\
\text { hyperthyroidism, } \\
\text { granulomatous disorders } \\
\text { such as sarcoidosis, } \\
\text { tuburculosis, and some } \\
\text { lymphomas }\end{array}$ \\
\hline
\end{tabular}

(2) older people admitted to hospital; (3) patients with hip fracture; (4) dark-skinned women (particularly if veiled); and (5) mothers of infants with rickets (particularly if dark-skinned or veiled). ${ }^{58}$

If electing to test vitamin D status, serum 25hydroxyvitamin $\mathrm{D}$ is the accepted biomarker. ${ }^{60} \mathrm{Al}$ though $1,25-\mathrm{OH}-\mathrm{D}$ is the active circulating form of vitamin $\mathrm{D}$, measuring this level is not helpful because it is quickly and tightly regulated by the kidney. True deficiency would be evident only by measuring 25-OH-D. Of note, questions have been raised regarding the need for standardization of assays. ${ }^{61}$ A large laboratory (Quest Diagnostics) recently reported the possibility of thousands of incorrect vitamin D level results. ${ }^{62}$ Sunlight exposure questionnaires are imprecise and are not currently recommended. ${ }^{63}$

Controversy exists regarding the optimum level of serum 25-hydroxyvitamin D in a healthy population. Most experts agree that serum vitamin D levels $<20 \mathrm{ng} / \mathrm{mL}$ represent deficiency. However, 
some experts recommend aiming for a higher minimum target level of $30 \mathrm{ng} / \mathrm{mL}$ of 25 -hydroxyvitamin $\mathrm{D}^{49}$ in a healthy population. Vitamin D intoxication can occur when serum levels are greater than $150 \mathrm{ng} / \mathrm{mL}$. Symptoms of hypervitaminosis D include fatigue, nausea, vomiting, and weakness probably caused by the resultant hypercalcemia. Of note, sun exposure alone cannot lead to vitamin $\mathrm{D}$ intoxication as excess vitamin $\mathrm{D}_{3}$ is destroyed by sunlight.

\section{Treatment}

Given concern about skin cancer, many patients and clinicians are cautious regarding sun exposure recommendations. However, exposure of arms and legs for 5 to 30 minutes between the hours of $10 \mathrm{Am}$ and 3 PM twice a week can be adequate to prevent vitamin D deficiency. ${ }^{59}$

Natural dietary sources of vitamin D include salmon, sardines, mackerel, tuna, cod liver oil, shiitake mushrooms, and egg yolk. ${ }^{58}$ Fortified foods include milk, orange juice, infant formulas, yogurts, butter, margarine, cheeses, and breakfast cereals. ${ }^{59}$

Over-the-counter multivitamin supplements frequently contain $400 \mathrm{IU}$ of vitamins $\mathrm{D}_{1}, \mathrm{D}_{2}$, or $\mathrm{D}_{3}$. Alternatively, over-the-counter vitamin $\mathrm{D}_{3}$ supplements can be found in 400, 800, 1000, and $2000 \mathrm{IU}$ strengths. Prescription-strength supplementation choices include vitamin $\mathrm{D}_{2}$ (ergocalciferol), which provides 50,000 IU per capsule, and vitamin $\mathrm{D}_{2}$ liquid (drisdol) at $8000 \mathrm{IU} / \mathrm{mL}^{59}$

To prevent vitamin $\mathrm{D}$ deficiency in healthy patients, the 1997 Institute of Medicine recommendations suggested a daily vitamin D intake of 200 IU for children and adults up to 50 years of age; $400 \mathrm{IU}$ for adults 51 to 70 years of age; and $600 \mathrm{IU}$ for adults 71 years or older. ${ }^{64}$ The upper limit recommended was $2000 \mathrm{IU}$ daily. However, some experts consider this to be too low and recommend that children and adults without adequate sun exposure consume 800 to 1000 IU daily to achieve adequate serum vitamin D levels. ${ }^{59}$

Treatment recommendations vary depending on the cause of the deficiency. For example, patients with chronic kidney disease are recommended to have $1000 \mathrm{IU}$ of vitamin $\mathrm{D}_{3}$ daily. ${ }^{59}$ The expected blood level response to a given vitamin $\mathrm{D}$ dose varies, probably because of differences in the cause of the deficit as well as the starting point for correction. A recent editorial reported that supple- mental intakes of 400 IU per day of vitamin D increase $25(\mathrm{OH}) \mathrm{D}$ concentrations by only 2.8 to $4.8 \mathrm{ng} / \mathrm{mL}(7-12 \mathrm{nmol} / \mathrm{L})$ and that daily intakes of approximately $1700 \mathrm{IU}$ are needed to raise these concentrations from 20 to $32 \mathrm{ng} / \mathrm{mL}$ (50-80 nmol/ L). ${ }^{65}$ Responses to vitamin $\mathrm{D}$ supplementation or sun exposure may vary by patient, so clinicians may need to continue to monitor abnormal levels.

\section{References}

1. Brannon PM, Yetley EA, Bailey RL, Picciano MF. Overview of the conference "Vitamin D and Health in the $21^{\text {st }}$ Century: an Update". Am J Clin Nutr 2008;88(Suppl):483S-90S.

2. Wolf M, Shah A, Gutierrez O, et al. Vitamin D levels and early mortality among incident hemodialysis patients. Kidney Int 2007;72:1004-13.

3. Inaguma D, Nagaya H, Hara K, et al. Relationship between serum 1,25-dihydroxyvitamin D and mortality in patients with pre-dialysis chronic kidney disease. Clin Exp Nephrol 2008;12:126-31.

4. Al-Aly Z. Vitamin D as a novel nontraditional risk factor for mortality in hemodialysis patients: the need for randomized trials. Kidney Int 2007;72:909_ 11.

5. Dobnig H, Pilz S, Scharnagl H, et al. Independent association of low serum 25-hydroxyvitamin D and 1,25-dihydroxyvitamin D levels with all-cause and cardiovascular mortality. Arch Intern Med 2008;168: 1340-9.

6. Melamed ML, Michos ED, Post W, Astor B. 25hydroxyvitamin D levels and the risk of mortality in the general population. Arch Intern Med 2008;168: 1629-37.

7. Autier P, Gandini S. Vitamin D supplementation and total mortality. Arch Intern Med 2007;167:1730-7.

8. Wang TJ, Pencina MJ, Booth SL, et al. Vitamin D deficiency and risk of cardiovascular disease. Circulation 2008;117:503-11.

9. Mathieu C, Gysemans C, Giulietti A, Bouillon R. Vitamin D and diabetes. Diabetologia 2005;48:1247-57.

10. Sloka S, Grant M, Newhook L. The geospatial relation between UV solar radiation and type 1 diabetes in Newfoundland. Acta Diabetol 2009; epub ahead of print.

11. Mathieu C, van Etten E, Decallonne B, et al. Vitamin D and 1,25-dihydroxyvitamin D3 as modulators in the immunesystem. J Steroid Biochem Mol Bio 2004;89-90:449-52.

12. Palomer X, González-Clemente JM, Blanco-Vaca F, Mauricio D. Role of vitamin D in the pathogenesis of type 2 diabetes mellitus. Diabetes Obes Metab 2008;10:185-97.

13. Danescu LG, Levy S, Levy J. Vitamin D and diabetes mellitus. Endocrine 2009;35:11-7.

14. Pittas AG, Lau J, Hu FB, Dawson-Hughes B. The 
role of vitamin $\mathrm{D}$ andcalcium in type 2 diabetes. A systematic review and meta-analysis. J Clin Endocrinol Metab 2007;92:2017-29.

15. Rodriguez-Martinez MA, Garcia-Cohen EC. Role of $\mathrm{Ca}++$ and vitamin $\mathrm{D}$ in the prevention and treatment of osteoporosis. Pharmacol Ther 2002;93:3749.

16. Cranney A, Weiler HA, O’Donnell S, Puil L. Summary of evidence-based review on vitamin D efficacy and safety in relation to bone health. Am J Clin Nutr 2008;88(Suppl):513S-9S.

17. Avenell A, Gillespie WJ, O'Connell DC. Vitamin D and vitamin $\mathrm{D}$ analogues for preventing fractures associated with involutional and postmenopausal osteoporosis. Cochrane Database Syst Rev 2005;(3): CD000227.

18. Boonen S, Lips P, Bouillon R, Bischoff-Ferrari HA, Vanderschueren D, Haetiens P. Need for additional calcium to reduce the risk of hip fracture with vitamin D supplementation: evidence from a comparative metaanalysis of randomized controlled trials. J Clin Endocrinol Metab 2007;92:1415-23.

19. Bischoff-Ferrari HA, Willett WC, Wong JB, et al. Prevention of nonvertebral fractures with oral vitamin D dose dependency. A meta-analysis of randomized controlled trials. Arch Intern Med 2009;169: 551-61.

20. Prince RL, Adustin N, Devine A, et al. Effects of ergocalciferol added to calcium on the risk of falls in elderly high-risk women. Arch Intern Med 2008; 168:103-8.

21. Broe KE, Chen TC, Weinberg J, et al. A higher dose of vitamin D reduces the risk of falls in nursing home residents: a randomized multiple-dose study. J Am Geriatr Soc 2007;55:234-9.

22. Bischoff-Ferrari HA, Dawson-Hughes B, Willett WC, et al. Effect of vitamin D on falls: a metaanalysis. JAMA 2004;291:1999-2006.

23. Osborne JE, Hutchinson PE. Vitamin D and systemic cancer: is this relevant to malignant melanoma? Br J Dermatol 2002;147:197-213.

24. Giovannucci E, Liu Y, Rimm EB, et al. Prospective study of predictors of vitamin D statius and cancer incidence and mortality in men. J Natl Cancer Inst 2006;98:451-9.

25. Freedman DM, Looker AC, Chang SC, Graubard BI. Prospective study of serum vitamin D and cancer mortality in the United States. J Natl Cancer Inst 2007;99:1594-602.

26. Garland CF, Garland FC, Gorham ED, et al. The role of vitamin $\mathrm{D}$ in cancer prevention. Am J Public Health 2006;96:252-61.

27. Lappe JM, Travers-Gustafson D, Davies KM, Recker RR, Heaney RP. Vitamin D and calcium supplementation reduces cancer risk: results of a randomized trial. Am J Clin Nutr 2007;85:1586-91.

28. Ebers GC. Environmental factors and multiple sclerosis. Lancet Neurol 2008;7:268-77.
29. Kampman MT, Wilsgaard T, Mellgren SI. Outdoor activities and diet in childhood and adolescence relate to MS risk above the Arctic Circle. J Neurol 2007;254:471-7.

30. Willer CJ, Dyment DA, Sadovnick AD, et al. Timing of birth and risk of multiple sclerosis: population-based study. BMJ 2005;330:120.

31. van der Mei IAF, Ponsonby A, Dwyer T, et al. Past exposure to sun, skin phenotype, and risk of multiple sclerosis: case-control study. BMJ 2003;327:316.

32. Holick MF. Sunlight and vitamin D for bone health and prevention of autoimmune diseases, cancers, and cardiovascular disease. Am J Clin Nutr 2004;80(6 Suppl):1678S-88S.

33. Adorini L, Penna G. Control of autoimmune diseases by the vitamin $\mathrm{D}$ endocrine system. Nat Clin Pract Rheumatol 2008;4:404-12.

34. Szodoray P, Nakken B, Gaal J, et al. The complex role of vitamin $\mathrm{D}$ in autoimmune diseases. Scand J Immunol 2008;68:261-9.

35. Munger KL, Levin LI, Hollis BW, Howard NS, Ascherio A. Serum 25-hydroxyvitamin D levels and risk of multiple sclerosis. JAMA 2006;296:2832-8.

36. Kragt JJ, van Amerongen BM, Killestein J, et al. Higher levels of 25-hydroxyvitamin D are associated with a lower incidence of multiple sclerosis only in women. Mult Scler 2009;15:9-15.

37. van der Mei IAF, Ponsonby A, Dwyer T, et al. Vitamin D levels in people with multiple sclerosis and community controls in Tasmania, Australia. J Neurol 2007;254:581-90.

38. Soilu-Hänninen M, Airas L, Mononen I, Heikkilä A, Viljanen M, Hänninen A. 25-Hydroxyvitamin D levels in serum at the onset of multiple sclerosis. Mult Scler 2005; 11:266-71.

39. Smolders J, Menheere P, Kessels A, Damoiseaux J, Hupperts R. Association of vitamin D metabolite levels with relapse rate and disability in multiple sclerosis. Mult Scler 2008;14:1220-4.

40. Brown SJ. The role of vitamin D in multiple sclerosis. Ann Pharmacother 2006;40:1158-61.

41. Munger KL, Zhang S.M, O'Reilly E, et al. Vitamin $\mathrm{D}$ intake and incidence of multiple sclerosis. Neurology 2004;62:60-5.

42. Smolders J, Damoiseaux J, Menheere P, Hupperts R. Vitamin D as an immune modulator in multiple sclerosis, a review. J Neuroimmunol 2008;194:7-17.

43. Kimball SM, Ursell MR, O'Connor P, Vieth R. Safety of vitamin D3 in adults with multiple sclerosis. Am J Clin Nutr 2007;86:645-51.

44. Buell JS, Dawson-Hughes B. Vitamin D and neurocognitive dysfunction: preventing "D"ecline? Mol Aspects Med 2008;29:415-22.

45. Oudshoorn C, Mattace-Raso FU, van der Velde N, Colin EM, van der Cammen TJ. Higher serum vitamin D3 levels are associated with better cognitive test performance in patients with Alzheimer's dis- 
ease. Dement Geriatr Cogn Disord 2008;25:53943.

46. Straube S, Andrew Moore R, McQuay HJ. Vitamin $\mathrm{D}$ and chronic pain. Pain 2009;141:10-3.

47. Heath KM, Elovic EP. Vitamin D deficiency: implications in the rehabilitation setting. Am J Phys Med Rehabil 203;85:916-23.

48. Wagner CL, Greer FR, American Academy of Pediatrics Section on Breastfeeding, American Academy of Pediatrics Committee on Nutrition. Prevention of rickets and vitamin D deficiency in infants, children, and adolescents. Pediatrics 2008;122:114252.

49. Hollis BW, Wagner CL. Assessment of dietary vitamin D requirements during pregnancy and lactation. Am J Clin Nutr 2004;79:717-26.

50. Gartner LM, Greer FR, American Academy of Pediatrics Section on Breastfeeding, American Academy of Pediatrics Committee on Nutrition. Prevention of rickets and vitamin $\mathrm{D}$ deficiency: new guidelines for vitamin D intake. Pediatrics 2003;111: 908-10.

51. Weisberg P, Scanlon K, Li R, Cogswell ME. Nutritional rickets among children in the United States: review of cases reported between 1986 and 2003. Am J Clin Nutr 2004;80(6 Suppl):1697S-1705S.

52. Vitamin D supplementation: recommendations for Canadian mothers and infants. Paediatr Child Health 2007;12:583-9.

53. Javaid MK, Crozier SR, Harvey NC, et al. Maternal vitamin $\mathrm{D}$ status during pregnancy and childhood bone mass at age 9 years: a longitudinal study. Lancet 2006;367:36-43.

54. Camargo CA Jr, Rifas-Shiman SL, Litonjua AA, et al. Maternal intake of vitamin $\mathrm{D}$ during pregnancy and risk of recurrent wheeze at $3 \mathrm{y}$ of age. Am J Clin Nutr 2007;85:788-95.

55. Tsang R, Zlotkin S, Nichols B, Hansen J. Nutrition during infancy: rinciples and ractice, 2 nd ed. Cincinnati, OH: Digital Education Publishing; 1997.
56. Wagner CL, Hulsey TC, Fanning D, Ebeling M, Hollis BW. High-dose vitamin D3 supplementation in a cohort of breastfeeding mothers and their infants: a 6-month follow-up pilot study. Breastfeed Med 2006;1:59-70.

57. Hollis BW, Taylor SN. Vitamin D requirements in pregnancy and lactation. Poster abstract at the 135th American Public Health Association Annual Meeting and Exposition; November 2007; Washington, DC.

58. Working Group of the Australian and New Zealand Bone and Mineral Society, Endocrine Society of Australia, Osteoporosis Australia. Vitamin D and adult bone health in Australia and New Zealand: a position statement. Med J Aust 2005;182:281-5.

59. Holick MF. Vitamin D deficiency. N Engl J Med 2007;357:266-81.

60. Millen AE, Bodnar LM Vitamin D assessment in population-based studies: a review of the issues. Am J Clin Nutr 2008;87(suppl):1102S-5S.

61. Binkley N, Krueger D, Cowgill CS, et al. Assay variation confounds the diagnosis of hypovitaminosis D: a call for standardization. J Clin Endocrinol Metab 2004;89:3152-7.

62. Pollack A. Quest acknowledges errors in vitamin D tests. Available at: http://www.nytimes.com/2009/ 01/08/business/08labtest.html. Accessed 17 September 2009 .

63. McCarty CA. Sunlight exposure assessment: can we accurately assess vitamin D exposure from sunlight questionnaires? Am J Clin Nutr 2008;87(Suppl): 1097S-101S.

64. Standing Committee on the Scientific Evaluation of Dietary Reference Intakes Food and Nutrition Board, Institute of Medicine. Vitamin D. In: Dietary reference intakes for calcium, phosphorus, magnesium, vitamin $\mathrm{D}$, and fluoride. Washington, DC: National Academy Press; 1997:250-87.

65. Vieth R, Bischoff-Ferrari H, Boucher BJ, et al. The urgent need to recommend an intake of vitamin $\mathrm{D}$ that is effective. Am J Clin Nutr 2007;85:649-50. 